\title{
Rheological approach for determining yield stresses in flowable resin composites prior to setting
}

\author{
Masaki ASAKURA ${ }^{1}$, Tatsuhide HAYASHI ${ }^{1}$, Shozo TSURUTA¹, Mitsunori YAMAMOTO², Shuichiro KOBAYASHI ${ }^{3}$, \\ Akimichi MIEKI ${ }^{1}$ and Tatsushi KAWAI ${ }^{1}$ \\ ${ }^{1}$ Department of Dental Materials Science, School of Dentistry, Aichi Gakuin University, 1-100 Kusumoto-cho, Chikusa-ku, Nagoya 464-8650, Japan \\ ${ }^{2}$ Department of Endodontics, School of Dentistry, Aichi Gakuin University, 2-11 Suemori-dori, Chikusa-ku, Nagoya 464-8651, Japan \\ ${ }^{3}$ Department of Periodontology, School of Dentistry, Aichi Gakuin University, 2-11 Suemori-dori, Chikusa-ku, Nagoya 464-8651, Japan \\ Corresponding author, Masaki ASAKURA; E-mail: masaki@dpc.agu.ac.jp
}

\begin{abstract}
The purpose of this study is to develop a method for quantifying the fluidity of flowable resin composites using determinations of yield stress. Five commercially available composites (AliteFlo LV, Flow-it ALC, Venus flow, Tetric N-flow, Revolution Formula2) were investigated. Yield stress values were obtained by plotting shear stresses for a range of shear rates, followed by fitting of Casson fluid models to flow curve data and extrapolation to the stress axis. To confirm that yield stress reflected fluidity, apparent viscosity at the lower shear rate $\left(0.2 \mathrm{~s}^{-1}\right)$ was calculated from flow curves. Yield stresses ranged from 5.4 to $43.1 \mathrm{~Pa}$, and were found to capture differences in the fluidity of composites that were not captured by viscosity measurement at the low shear rate. Yield stress is directly proportional to fluidity, and could serve as a simple and precise indicator for selecting flowable resin composites for use in various clinical applications.
\end{abstract}

Keywords: Flowable resin composites, Yield stress, Rheology, Handling characteristics

\section{INTRODUCTION}

Selection of flowable resin composites with handling properties that are appropriate for specific clinical situations is an important factor in successful dental restoration. For placement of these materials, flow properties are particularly important. Flowable resin composites have a wide range of clinical applications, including use as pit and fissure sealants and restoration liners and in Class IV and V restorations, and accordingly have widely varying flow properties ${ }^{1}$. However, because no standard test method for evaluating the flow properties of these materials has been described, products often lack absolute assessments. Instead, manufacturers only report comparisons of flow distances of resin composites on a vertical plane. Previous studies report flow properties of flowable resin composites using various methods, including the flow test specified in ADA and ISO standards ${ }^{2,3)}$ with modification ${ }^{4-6)}$, measurements of aspect ratios of slumped composites after extrusion ${ }^{7)}$, and rheometer-based measurements of dynamic flow properties ${ }^{8-13}$. Among these methods, dynamic rheological measurements are the most accurate for flowable resin composites. However, because these materials behave as non-Newtonian fluids, their flow properties vary widely under different shear conditions, and accurate interpretations of measurements remain beyond the expertise of most clinicians.

Flowable resin composites are formed by suspending solid ceramic particles in resin matrixes, resulting in viscoplastic fluids that can be characterized according to

Color figures can be viewed in the online issue, which is available at J-STAGE.

Received May 2, 2016: Accepted Jan 19, 2017

doi:10.4012/dmj.2016-164 JOI JST.JSTAGE/dmj/2016-164 yield stresses. Yield stresses of viscoplastic materials are defined as the required shear stress for initiation of flow, and also explain inhibition of flow under the relatively low stress induced by gravity. Thus, yield stress relates directly to fluidity, which is defined as flow by weight, and yield stress measurements using rheological methods have been used to evaluate the fluidity of suspensions of solid particles, such as ink, paint, cosmetic creams, food pastes, chocolates, and cement ${ }^{14-18}$.

The aim of this study was to develop an appropriate method for measuring yield stresses of flowable resin composites and to quantify fluidity and handling characteristics. The null hypothesis was that there is no significant difference in yield stress among flowable resin composites used in this study.

\section{METHODS AND MATERIALS}

Five commercial flowable resin composites were tested in this study: AliteFlo LV (AF: Bisco, Schaumburg, IL, USA), Flow-it ALC (FI: Jeneric/Pentron, Wallingford, CT, USA), Venus flow (VF: Heraeus-Kulzer, Weihrheim, Germany), Tetric N-flow (TF: Ivoclar-Vivadent, Schaan, Liechtenstein), and Revolution Formula2 (RV: Kerr, Orange, CA, USA) (Table 1).

\section{Rheological measurements}

Rheological measurements were performed using a viscometer (RE-215U, TOKI SANGYO, Tokyo, Japan) and a cone-and-plate module with a cone radius of 24 $\mathrm{mm}$ and a cone angle of $1^{\circ} 34^{\prime}$. Diagram of the cone-andplate rotational viscometer is shown in Fig. 1. The cone is driven by the motor at variable rotational speed and 
Table 1 Flowable resin composites and composition according to the manufacturer's information

\begin{tabular}{|c|c|c|c|c|c|}
\hline \multirow{2}{*}{ Code } & \multirow{2}{*}{ Brand name } & \multirow{2}{*}{ Manufacture } & \multirow{2}{*}{ Resin matrix } & \multicolumn{2}{|c|}{ Filler content } \\
\hline & & & & Size $(\mu \mathrm{m})$ & Load (wt.\%) \\
\hline $\mathrm{AF}$ & AliteFlo LV & Bisco, Schaumburg, IL, USA & Bis-GMA, TEGDMA & $0.03-0.7$ & 60 \\
\hline FI & Flow-it ALC & $\begin{array}{l}\text { Jeneric/Pentron, Wallingford, } \\
\text { CT, USA }\end{array}$ & $\begin{array}{l}\text { Bis-GMA, TEGDMA, } \\
\text { EBADMA }\end{array}$ & $0.04-4$ & 66 \\
\hline $\mathrm{VF}$ & Venus flow & $\begin{array}{l}\text { Heraeus-Kulzer, Weihrheim, } \\
\text { Germany }\end{array}$ & TEGDMA, EBADMA & $0.005-5$ & 62 \\
\hline $\mathrm{TF}$ & Tetric N-Flow & $\begin{array}{l}\text { Ivoclar-Vivadent, Schaan, } \\
\text { Liechtenstein }\end{array}$ & $\begin{array}{l}\text { Bis-GMA, TEGDMA, } \\
\text { UDMA }\end{array}$ & $0.04-3$ & 63.8 \\
\hline $\mathrm{RV}$ & Revolution formura2 & Kerr, Orange, CA, USA & Bis-GMA, EBADMA & Ave. 0.6 & 60 \\
\hline
\end{tabular}

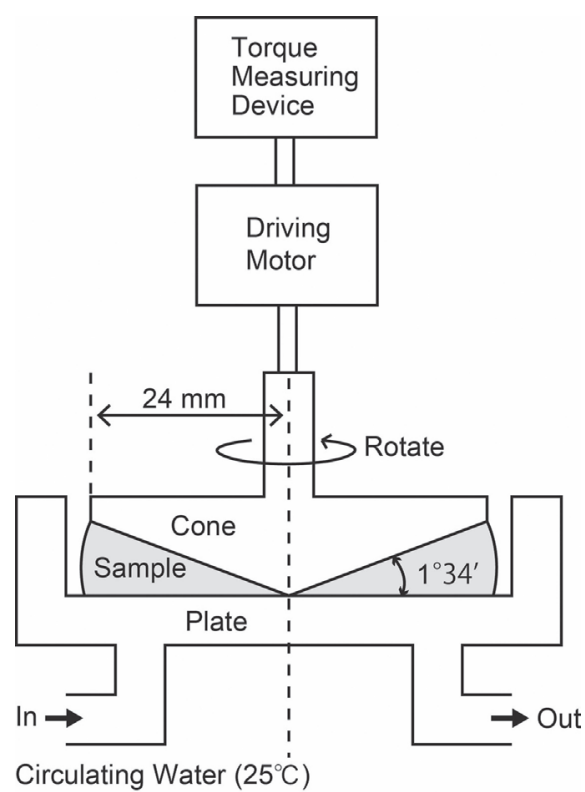

Fig. 1 Diagram of the cone-and-plate rotational viscometer.

sample is sheared in the narrow gap between the cone and the plate. The resistance to the rotation of the cone, which is caused by presence of the sample, is measured by the torque measuring device. The shear stress can be calculated from this reading and the geometric constant of the cone. All measurements were performed at $25^{\circ} \mathrm{C}$. Composites $(1.1 \mathrm{~mL})$ were extruded onto the plate as slowly as possible through a syringe with no needle. After residual stress was removed, composites were presheared at a shear rate of $40 \mathrm{~s}^{-1}$ for $3 \mathrm{~s}$. This shear rate was determined by calculating the average shear rate of composites that were extruded through a syringe and needle with an internal radius of $0.4 \mathrm{~mm}$ at a volumetric flow rate of $3 \mathrm{~mm}^{3} \mathrm{~s}^{-1}$. Accordingly, maximum wall shear rates of material flows through circular tubes can be calculated based on the internal radius of the tube and the volumetric flow rate using Eq. (1), which is derived from the standard Hagen-Poiseuille equation.

$$
G_{\text {wall }}=4 Q / \pi R^{3}
$$

Here, $G_{\text {wall }}$ is the maximum wall shear rate $\left(\mathrm{s}^{-1}\right), Q$ is the volumetric flow rate $\left(\mathrm{mm}^{3} \mathrm{~s}^{-1}\right)$, and $R$ is the internal radius of the tube $(\mathrm{mm})$.

Gregory ${ }^{19)}$ showed that the average shear rate is twothirds of the maximum wall shear rate using Eq. (2).

$$
G_{\text {average }}=8 Q / 3 \pi R^{3}
$$

Here, $G_{\text {average }}$ is the average shear rate $\left(\mathrm{s}^{-1}\right)$.

Pre-shearing times were determined by calculating residence times of composites in an 18-mm long needle during extrusion from a syringe. After pre-shearing, flow curves were obtained by measuring shear stress $(\mathrm{Pa})$ at various low shear rates of $0.2-1.0 \mathrm{~s}^{-1}$. To accommodate the time taken for the viscometer reach equilibrium, Shear rates were monitored until the observed values became stable, and the required time for measurements depended on both shear rates and flow properties of samples. All measurements were repeated three times for each material.

\section{Determination of yield stress}

Yield stress refers to the highest stress at which a material resists flow, that is, the stress at which the slightest increase in stress will initiate flow. Accordingly, in rheological analyses, yield stress can be defined as shear stress at a shear rate of zero. Experimental application of this definition gives accurate approximations of yield stress from plots of shear stress values over a range of shear rates followed by extrapolation of fitted mathematical models of flow curve data (Fig. 2). In this study, we employed the Casson model (Eq. (3)), which is a well-known rheological model that is suitable for viscoplastic fluids.

$$
\sigma^{1 / 2}=\sigma_{c}^{1 / 2}+\eta_{c}^{1 / 2} \dot{\gamma}^{1 / 2}
$$

Here, $\sigma$ is shear stress $(\mathrm{Pa}), \dot{\gamma}$ is the shear rate $\left(\mathrm{s}^{-1}\right), \sigma_{c}$ is the Casson yield stress $(\mathrm{Pa})$, and $\eta_{c}$ is Casson plastic viscosity $(\mathrm{Pa} \cdot \mathrm{s})$.

A simple method for fitting data with the Casson 
model involves plotting the square root of the shear stress versus that of the shear rate (Casson plot). The resulting linear plots facilitate extrapolation to the zero shear rate, and the yield stress is then determined as the square of the value at the intercept, which is obtained

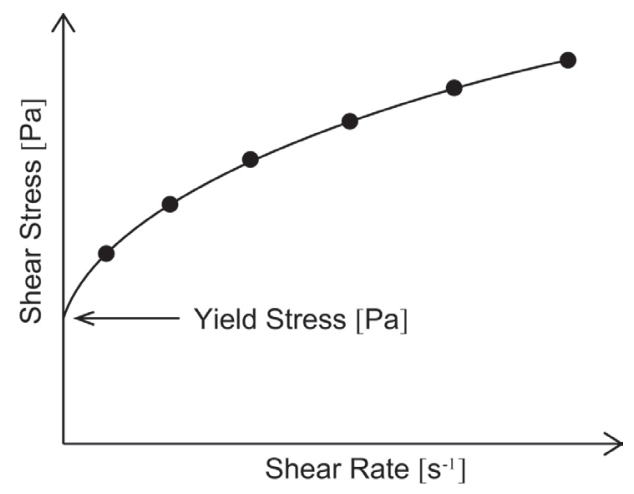

Fig. 2 Schematic of the rheological method for determining yield stress.

Yield stress can be assessed by plotting shear stress values over a range of shear rates, followed by fitting of flow curve data to mathematical models and extrapolation to the stress axis. by numerically extrapolating the Casson plot data to the stress axis. To assess how well the model fits the experimental data, the coefficient of determination $\left(R^{2}\right)$ was calculated.

Determination of apparent viscosity

To compare the accuracy of yield stress and apparent viscosity measurements of fluidity, the apparent viscosity at the lowest shear rate $\left(0.2 \mathrm{~s}^{-1}\right)$ was calculated from the rheological measurement according to Eq. (4).

$$
\eta=\sigma / \dot{\gamma}
$$

Here, $\eta$ is apparent viscosity $(\mathrm{Pa} \cdot \mathrm{s}), \sigma$ is the shear stress $(\mathrm{Pa})$, and $\dot{\gamma}$ is the shear rate $\left(\mathrm{s}^{-1}\right)$.

\section{Statistical analysis}

Significant differences in yield stresses and apparent viscosity measurements were identified using Tukey multiple comparison tests. A $p$ value less than 0.05 was regarded as indicating statistical significance.

\section{RESULTS}

All data from flow curves and Casson plots are shown in Figs. 3 and 4, respectively, and typical flow curves for
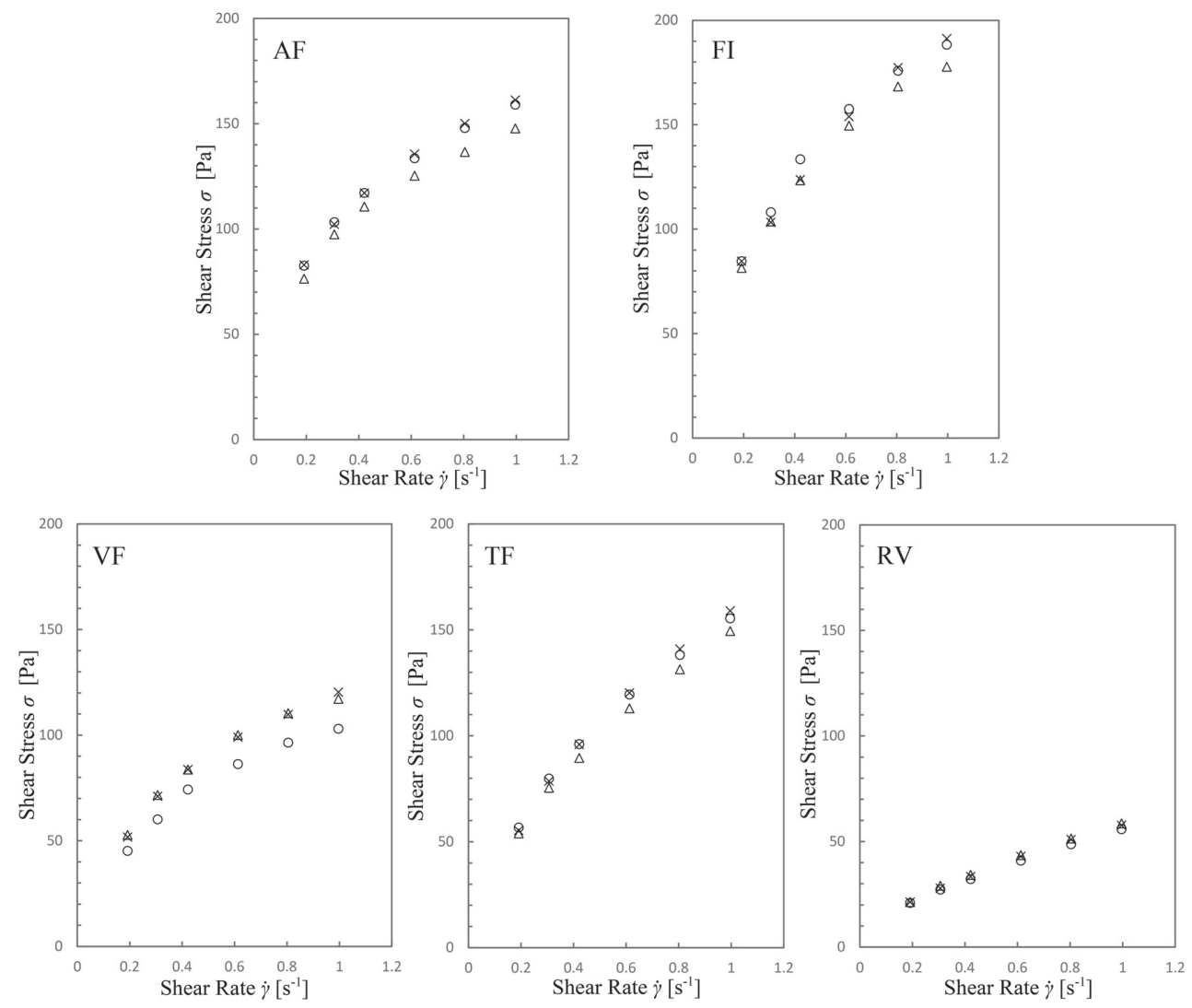

Fig. 3 Flow curves $(n=3)$. 

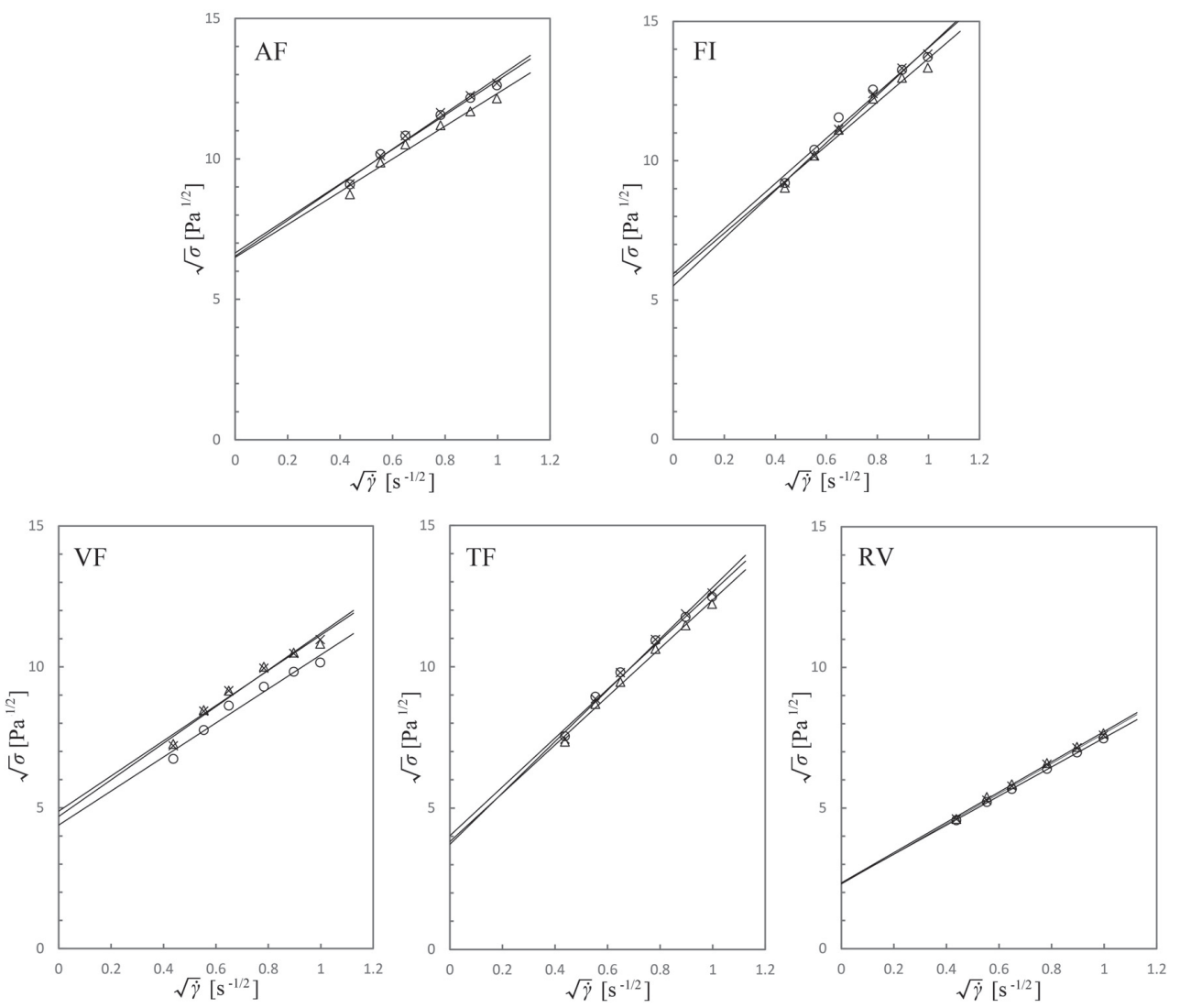

Fig. 4 Casson plots $(n=3)$.
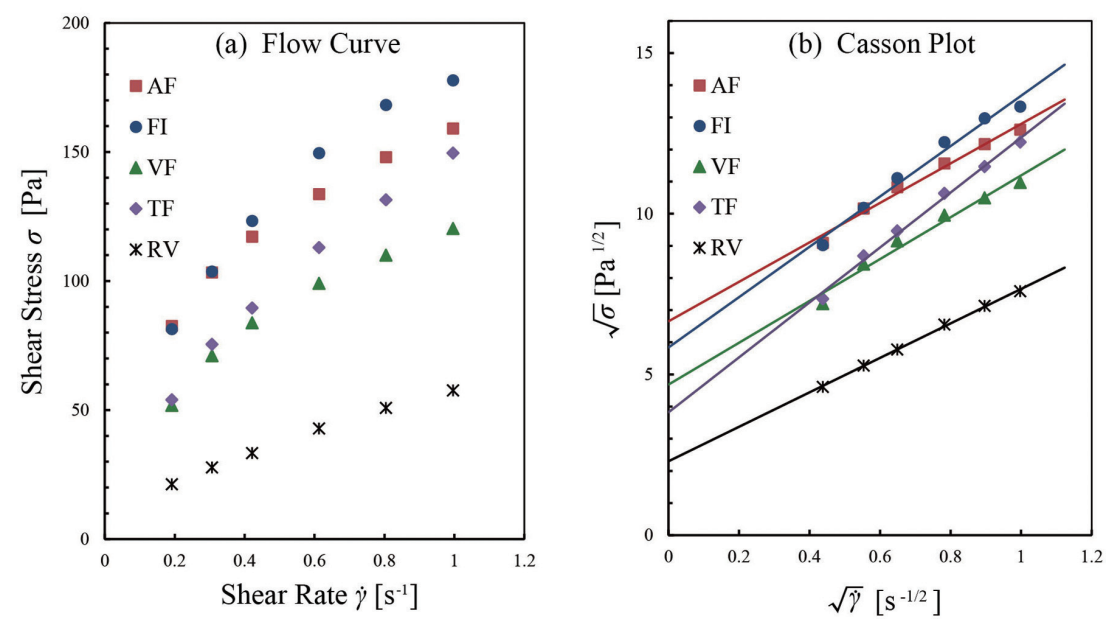

Fig. 5 Typical flow curves of shear stress versus shear rate (a) and typical Casson plots of the square root of shear stress versus the square root of the shear rate (b).

Flow curves show that all samples have non-Newtonian shear-thinning behaviors. Casson plots were approximately linear for all samples.

shear stresses versus shear rates are shown in Fig. 5(a). In these analyses, all samples exhibited non-Newtonian shear-thinning behaviors. Moreover, Casson plots of the square root of the shear stress versus the square root of the shear rate were approximately linear for all samples (Fig. 5(b)), and fitted well with the Casson model, as indicated by the $R^{2}$ values (Table 2). Obtained yield stresses and apparent viscosities are shown in Table 2. 
Table 2 Yield stress, coefficients of determination $\left(R^{2}\right)$ for the Casson model, and apparent viscosity of flowable resin composites

\begin{tabular}{|c|c|c|c|c|c|}
\hline \multirow{2}{*}{ Code } & \multicolumn{3}{|c|}{ Yield stress } & \multicolumn{2}{|c|}{ Apparent viscosity at $0.2 \mathrm{~s}^{-1}$} \\
\hline & Mean $(\mathrm{Pa})$ & S.D. (Pa) & $R^{2}$ & Mean $(\mathrm{Pa} \cdot \mathrm{s})$ & S.D. $(\mathrm{Pa} \cdot \mathrm{s})$ \\
\hline $\mathrm{AF}$ & $43.1^{\mathrm{a}}$ & 1.06 & $0.972-0.986$ & $421.4^{\mathrm{A}}$ & 19.2 \\
\hline FI & $33.3^{\mathrm{b}}$ & 2.55 & $0.975-0.992$ & $436.3^{\mathrm{A}}$ & 9.6 \\
\hline $\mathrm{VF}$ & $21.6^{c}$ & 2.31 & $0.964-0.972$ & $261.0^{\mathrm{B}}$ & 21.4 \\
\hline $\mathrm{TF}$ & $14.9^{\mathrm{d}}$ & 1.19 & $0.989-0.993$ & $289.3^{\text {B }}$ & 7.3 \\
\hline RV & $5.4^{\mathrm{e}}$ & 0.09 & 0.997-0.999 & $110.3^{\mathrm{C}}$ & 1.2 \\
\hline
\end{tabular}

Different superscript letters for each column indicate a significant difference $(p<0.05)$

Yield stresses ranged from 5.4 $\mathrm{Pa}$ for RV to 43.1 $\mathrm{Pa}$ for $\mathrm{AF}$, and varied significantly between the five composites in the following order: $\mathrm{AF}>\mathrm{FI}>\mathrm{VF}>\mathrm{TF}>\mathrm{RV}$. Meanwhile, apparent viscosity did not differ significantly between $\mathrm{AF}$ and FI, or between VF and TF, but varied from 110.0 $\mathrm{Pa} \cdot \mathrm{s}$ for $\mathrm{RV}$ to $436.3 \mathrm{~Pa} \cdot \mathrm{s}$ for FI in the following order: $\mathrm{FI}>\mathrm{AF}>\mathrm{TF}>\mathrm{VF}>\mathrm{RV}$.

\section{DISCUSSION}

In this study, we assumed that yield stress measurements are applicable to flow properties of resin composites, and determined yield stresses by fitting the Casson fluid model to the flow curve data using a standard rheological apparatus comprising a simple cone-and-plate rotational viscometer. Although the flow property of conventional non-flowable resin composites would provide useful information for comparison, we evaluated only flowable resin composites because conventional composites had too high flow resistance to measure yield stress. The Casson model is based on a structural model of interactive behaviors of solid and liquid phases in two-phase suspensions. However, this model is only applicable when flow curve data fit well. In a preliminary study, the Herschel-Bulkley model, which is a well-known alternative to the Casson model, was used to calculate yield stresses from fitted data, but returned meaningless negative yield stress data and was deemed inappropriate for descriptions of flowable resin composites. However, the present $R^{2}$ values (Table 2) from the Casson model indicated sufficient accuracy of flow measurements of the present composites to be considered an appropriate basis for measurement.

During yield stress measurements of thixotropic materials such as resin composites, constant pretreatments are essential. Moreover, a previous interlaboratory study of yield stresses ${ }^{20}$ indicated that uniform sample preparation and conditioning procedures and well-controlled shear histories are critical for accurate and reproducible estimations. Accordingly, excess or deficient pre-treatments result in mismatches between measured values and the flow properties exhibited in actual clinical conditions.
Flowable resin composites are usually applied via extrusion from syringes with needle attachments, which compromise internal structure and change flow properties. Beun et al. ${ }^{21)}$ indicated the need for consideration of these effects and Lee et al. ${ }^{7}$ controlled for the effects of shear history by measuring the slump of flowable resin composites after extrusion from a syringe using a custom-made loading device. Accordingly, in this study, sample pre-treatments were conducted carefully so that pre-shearing could be performed under conditions equivalent to the extrusion of flowable resin from a syringe. This approach may contribute to reproducibility and better agreement with actual clinical conditions.

Unlike previous rheological studies, in which the fluidity of flowable resin composites was evaluated according to viscosities under low shear conditions ${ }^{7,22)}$, we evaluated fluidity using yield stress (defined as shear stress at a shear rate of zero) approximations from shear stresses at low shear rates of $0.2-1.0 \mathrm{~s}^{-1}$. Because the shear rate of $0.2 \mathrm{~s}^{-1}$ is close to the lower limits of common viscometers, flow curves of shear stress versus shear rate (Fig. 5(a)) showed no differences between shear stresses of AF and FI at the shear rate of 0.2 $\mathrm{s}^{-1}$, suggesting no differences in apparent viscosities. Although these observations were confirmed in static analyses, the yield stress of $\mathrm{AF}$ was higher than that of FI and was similar for VF and TF. These results demonstrate that yield stress measurements can be used to detect differences in fluidity that cannot be shown using measurements of apparent viscosity at low shear rates. Hence, we conclude that yield stress measurements are more suitable than apparent viscosities for evaluating the fluidity of flowable resin composites. Furthermore, because the method can be performed using a simple viscometer and does not require the use of a costly rheometer, it is preferable as a standard method for evaluating the fluidity of flowable resin composites.

The yield stress of RV was much lower than that of the other four resin composites, indicating that RV has high fluidity and would have the most suitable handling properties for use as a restoration liner and as a pit and fissure sealant. However, although AF is categorized as a low-viscosity type by its manufacturer, it was 
found to have the lowest fluidity among the materials tested and would therefore be useful for Class IV and V restorations.

Further studies are required to validate this method and determine reproducibility of yield stress measurements among different laboratories.

\section{CONCLUSION}

Given the comparative simplicity and precision of the proposed method for measuring yield stress, it should provide a useful indicator for selecting flowable resin composites with suitable handling properties for various clinical applications.

\section{REFERENCES}

1) Moon PC, Tabassian MS, Culbreath TE. Flow characteristics and film thickness of flowable resin composites. Oper Dent 2002; 27: 248-253.

2) ANSI/ADA Standard No. 30 -Dental Zinc Oxide - Eugenol and Zinc Oxide-Non-Eugenol Cements: 2013.

3) ISO 3107: 2011, Dentistry —Zinc oxide/eugenol cements and zinc oxide/non-eugenol cements.

4) Attar N, Tam LE, McComb D. Flow, strength, stiffness and radiopacity of flowable resin composites. J Can Dent Assoc 2003; 69: 516-521.

5) Bayne SC, Thompson JY, Swift EJ Jr, Stamatiades P, Wilkerson M. A characterization of first-generation flowable composites. J Am Dent Assoc 1998; 129: 567-577.

6) Deb S, Di Silvio L, Mackler HE, Millar BJ. Pre-warming of dental composites. Dent Mater 2011; 27: e51-59.

7) Lee IB, Min SH, Kim SY, Ferracane J. Slumping tendency and rheological properties of flowable composites. Dent Mater 2010; 26: 443-438

8) Al-Ahdal K, Silikas N, Watts DC. Rheological properties of resin composites according to variations in composition and temperature. Dent Mater 2014; 30: 517-524.

9) Beun S, Bailly C, Dabin A, Vreven J, Devaux J, Leloup G. Rheological properties of experimental Bis-GMA/TEGDMA flowable resin composites with various macrofiller/microfiller ratio. Dent Mater 2009; 25: 198-205.

10) Beun S, Bailly C, Devaux J, Leloup G. Physical, mechanical and rheological characterization of resin-based pit and fissure sealants compared to flowable resin composites. Dent Mater 2012; 28: 349-359.

11) Lee IB, Cho BH, Son HH, Um CM. Rheological characterization of composites using a vertical oscillation rheometer. Dent Mater 2007; 23: 425-432.

12) Lee IB, Son HH, Um CM. Rheologic properties of flowable, conventional hybrid, and condensable composite resins. Dent Mater 2003; 19: 298-307.

13) Lee JH, Um CM, Lee IB. Rheological properties of resin composites according to variations in monomer and filler composition. Dent Mater 2006; 22: 515-526.

14) Baker BS, Brown BD, Anantheswaran RC. Measurement of yield stress in dark chocolate using controlled stress vane method. J Texture Stud 2006; 37: 655-667.

15) Clayton S, Grice TG, Boger DV. Analysis of the slump test for on-site yield stress measurement of mineral suspensions. Int J Miner Process 2003; 70: 3-21.

16) De Graef V, Depypere F, Minnaert M, Dewettinck K. Chocolate yield stress as measured by oscillatory rheology. Food Res Int 2011; 44: 2660-2665.

17) Nakagawa $Y$, Ueda T. The application of rheology in the development of unique cosmetics. J Soc Rheol Jpn 2010; 38: 175-180.

18) Sun A, Gunasekaran S. Yield stress in foods: Measurements and applications. Int J Food Prop 2009; 12: 70-101.

19) Gregory J. Flocculation in laminar tube flow. Chem Eng Sci 1981; 36: 1789-1794

20) Nguyen QD, Akroyd T, De Kee DC, Zhu L. Yield stress measurements in suspensions: An inter-laboratory study. Korea-Aust Rheol J 2006; 18: 15-24.

21) Beun S, Bailly C, Devaux J, Leloup G. Rheological properties of flowable resin composites and pit and fissure sealants. Dent Mater 2008; 24: 548-555.

22) Petrovic LM, Zorica DM, Stojanac I, Krstonosic VS, Hadnadjev MS, Atanackovic TM. A model of the viscoelastic behavior of flowable resin composites prior to setting. Dent Mater 2013; 29: 929-934. 